\title{
SEMI DERIVATIONS OF PRIME GAMMA RINGS
}

\author{
Kalyan Kumar Dey ${ }^{1}$ and Akhil Chandra Paul ${ }^{2}$ \\ ${ }^{1,2}$ Department of Mathematics \\ Rajshahi University, Rajshahi-6205, Bangladesh \\ 1'kkdmath@yahoo.com; 2acpaulru_math@yahoo.com
}

Received 25.4.2011 $\quad$ Accepted 28.12.2012

\begin{abstract}
Let $\mathrm{M}$ be a prime $\Gamma$-ring satisfying a certain assumption $\left(^{*}\right)$. An additive mapping $\mathrm{f}: \mathrm{M} \rightarrow \mathrm{M}$ is a semi-derivation if $\mathrm{f}(\mathrm{x} \alpha \mathrm{y})=\mathrm{f}(\mathrm{x}) \alpha \mathrm{g}(\mathrm{y})+\mathrm{x} \alpha \mathrm{f}(\mathrm{y})=\mathrm{f}(\mathrm{x}) \alpha \mathrm{y}+\mathrm{g}(\mathrm{x}) \alpha \mathrm{f}(\mathrm{y})$ and $\mathrm{f}(\mathrm{g}(\mathrm{x}))=\mathrm{g}(\mathrm{f}(\mathrm{x}))$ for all $\mathrm{x}$, $y \in M$ and $\alpha \in \Gamma$, where $g: M \rightarrow M$ is an associated function. In this paper, we generalize some properties of prime rings with semi-derivations to the prime $\Gamma$-rings with semi-derivations.
\end{abstract}

2000 AMS Subject Classifications: 16A70, 16A72, 16A10.

Keywords: Semi derivation, Prime gamma ring, Commuting mapping

\section{Introduction}

J. C. Chang [6] worked on semi-derivations of prime rings. He obtained some results of derivations of prime rings into semi-derivations. H. E. Bell and W. S. Martindale III [1] investigated the commutativity property of a prime ring by means of semi-derivations. C. L. Chuang [7] studied on the structure of semi-derivations in prime rings. He obtained some remarkable results in connection with the semi-derivations. J. Bergen and P. Grzesczuk [3] obtained the commutativity properties of semiprime rings with the help of skew (semi)-derivations. A. Firat [8] generalized some results of prime rings with derivations to the prime rings with semi-derivations.

In this paper, we generalize some results of prime rings with semi-derivations to the prime $\Gamma$-rings with semi-derivations.

\section{Preliminaries}

Let $M$ and $\Gamma$ be additive abelian groups. $M$ is called a $\Gamma$-ring if for all $x, y, z \in M, \alpha, \beta \in \Gamma$ the following conditions are satisfied:

(i) $x \beta y \in M$,

(ii) $(\mathrm{x}+\mathrm{y}) \alpha z=\mathrm{x} \alpha z+\mathrm{y} \alpha z, \mathrm{x}(\alpha+\beta) \mathrm{y}=\mathrm{x} \alpha y+\mathrm{x} \beta y, \mathrm{x} \alpha(\mathrm{y}+\mathrm{z})=\mathrm{x} \alpha y+\mathrm{x} \alpha z$,

(iii) $(\mathrm{x} \alpha y) \beta z=\mathrm{x} \alpha(\mathrm{y} \beta \mathrm{z})$.

Let $\mathrm{M}$ be a $\Gamma$-ring with center $\mathrm{C}(\mathrm{M})$. For any $\mathrm{x}, \mathrm{y} \in \mathrm{M}$, the notation $[\mathrm{x}, \mathrm{y}]_{\alpha}$ and $(\mathrm{x}, \mathrm{y})_{\alpha}$ will denote $\mathrm{x} \alpha \mathrm{y}-\mathrm{y} \alpha \mathrm{x}$ and $\mathrm{x} \alpha \mathrm{y}+\mathrm{y} \alpha \mathrm{x}$ respectively. We know that $[\mathrm{x} \beta \mathrm{y}, \mathrm{z}]_{\alpha}=\mathrm{x} \beta[\mathrm{y}, \mathrm{z}]_{\alpha}+$ $[\mathrm{x}, \mathrm{z}]_{\alpha} \beta \mathrm{y}+\mathrm{x}[\beta, \alpha]_{\mathrm{z}} \mathrm{y}$ and $[\mathrm{x}, \mathrm{y} \beta \mathrm{z}]_{\alpha}=\mathrm{y} \beta[\mathrm{x}, \mathrm{z}]_{\alpha}+[\mathrm{x}, \mathrm{y}]_{\alpha} \beta \mathrm{z}+\mathrm{y}[\beta, \alpha]_{\mathrm{x}} \mathrm{z}$, for all $\mathrm{x}, \mathrm{y}, \mathrm{z} \in \mathrm{M}$ and for 
all $\alpha, \beta \in \Gamma$. We shall take an assumption $\left({ }^{*}\right) \mathrm{x} \alpha \mathrm{y} \beta \mathrm{z}=\mathrm{x} \beta \mathrm{y} \alpha \mathrm{z}$ for all $\mathrm{x}, \mathrm{y}, \mathrm{z} \in \mathrm{M}, \alpha, \beta \in \Gamma$. Using the assumption (*) the identities $[\mathrm{x} \beta \mathrm{y}, \mathrm{z}]_{\alpha}=\mathrm{x} \beta[\mathrm{y}, \mathrm{z}]_{\alpha}+[\mathrm{x}, \mathrm{z}]_{\alpha} \beta \mathrm{y}$ and $[\mathrm{x}, \mathrm{y} \beta \mathrm{z}]_{\alpha}=\mathrm{y} \beta[\mathrm{x}, \mathrm{z}]_{\alpha}+[\mathrm{x}, \mathrm{y}]_{\alpha} \beta \mathrm{z}$, for all $\mathrm{x}, \mathrm{y}, \mathrm{z} \in \mathrm{M}$ and for all $\alpha, \beta \in \Gamma$ are used extensively in our results. So we make extensive use of the basic commutator identities: $(x \beta y, z)_{\alpha}=(x$, $\mathrm{z})_{\alpha} \beta \mathrm{y}+\mathrm{x} \beta[\mathrm{y}, \mathrm{z}]_{\alpha}=[\mathrm{x}, \mathrm{z}]_{\alpha} \beta \mathrm{y}+\mathrm{x} \beta(\mathrm{y}, \mathrm{z})_{\alpha} . \mathrm{A} \Gamma$-ring $\mathrm{M}$ is to be $\mathrm{n}$-torsion free if $\mathrm{nx}=0$, $\mathrm{x} \in \mathrm{M}$ implies $\mathrm{x}=0$. Recall that a $\Gamma$-ring $\mathrm{M}$ is prime if $\mathrm{x} \Gamma \mathrm{M} \Gamma \mathrm{y}=0$ implies that $\mathrm{x}=0$ or $\mathrm{y}$ $=0$.

A mapping $\mathrm{D}$ from $\mathrm{M}$ to $\mathrm{M}$ is said to be commuting on $\mathrm{M}$ if $[\mathrm{D}(\mathrm{x}), \mathrm{x}]_{\alpha}=0$ holds for all $\mathrm{x} \in \mathrm{M}, \alpha \in \Gamma$, and is said to be centralizing on $\mathrm{M}$ if $[\mathrm{D}(\mathrm{x}), \mathrm{x}]_{\alpha} \in \mathrm{C}(\mathrm{M})$ holds for all $\mathrm{x} \in \mathrm{M}$, $\alpha \in \Gamma$. An additive mapping $D$ from $M$ to $M$ is called a derivation if $D(x \alpha y)=D(x) \alpha y+$ $\mathrm{x} \alpha \mathrm{D}(\mathrm{y})$ holds for all $\mathrm{x}, \mathrm{y} \in \mathrm{M}, \alpha \in \Gamma$.

Let $\mathrm{M}$ be a $\Gamma$-ring. An additive mapping $\mathrm{d}$ : $\mathrm{M} \rightarrow \mathrm{M}$, is called a semi-derivation associated with a function $\mathrm{g}: \mathrm{M} \rightarrow \mathrm{M}$, if, for all $\mathrm{x}, \mathrm{y} \in \mathrm{M}, \alpha \in \Gamma$,

(i) $d(x \alpha y)=d(x) \alpha g(y)+x \alpha d(y)=d(x) \alpha y+g(x) \alpha d(y)$,

(ii) $\mathrm{d}(\mathrm{g}(\mathrm{x}))=\mathrm{g}(\mathrm{d}(\mathrm{x}))$.

If $\mathrm{g}=\mathrm{I}$, i.e., an identity mapping of $\mathrm{M}$, then all semi-derivations associated with $\mathrm{g}$ are merely ordinary derivations. If $\mathrm{g}$ is any endomorphism of $\mathrm{M}$, then other examples of semi-derivations are of the form $\mathrm{d}(\mathrm{x})=\mathrm{x}-\mathrm{g}(\mathrm{x})$.

\section{Example 2.1}

Let $\mathrm{M}_{1}$ be a $\Gamma_{1}$ ring and $\mathrm{M}_{2}$ be a $\Gamma_{2}$-ring. Consider $\mathrm{M}=\mathrm{M}_{1} \times \mathrm{M}_{2}$ and $\Gamma=\Gamma_{1} \times \Gamma_{2}$.

Define addition and multiplication on $\mathrm{M}$ and $\Gamma$ by

$$
\begin{aligned}
& \left(\mathrm{m}_{1}, \mathrm{~m}_{2}\right)+\left(\mathrm{m}_{3}, \mathrm{~m}_{4}\right)=\left(\mathrm{m}_{1}+\mathrm{m}_{3}, \mathrm{~m}_{2}+\mathrm{m}_{4}\right), \\
& \left(\alpha_{1}, \alpha_{2}\right)+\left(\alpha_{3}, \alpha_{4}\right)=\left(\alpha_{1}+\alpha_{3}, \alpha_{2}+\alpha_{4}\right), \\
& \left(\mathrm{m}_{1}, \mathrm{~m}_{2}\right)\left(\alpha_{1}, \alpha_{2}\right)\left(\mathrm{m}_{3}, \mathrm{~m}_{4}\right)=\left(\mathrm{m}_{1} \alpha_{1} \mathrm{~m}_{3}, \mathrm{~m}_{2} \alpha_{2} \mathrm{~m}_{4}\right),
\end{aligned}
$$

for every $\left(\mathrm{m}_{1}, \mathrm{~m}_{2}\right),\left(\mathrm{m}_{3}, \mathrm{~m}_{4}\right) \in \mathrm{M}$ and $\left(\alpha_{1}, \alpha_{2}\right),\left(\alpha_{3}, \alpha_{4}\right) \in \Gamma$.

Under these addition and multiplication $\mathrm{M}$ is a $\Gamma$-ring. Let $\delta: \mathrm{M}_{1} \rightarrow \mathrm{M}_{1}$ be an additive map and $\tau: \mathrm{M}_{2} \rightarrow \mathrm{M}_{2}$ be a left and right $\mathrm{M}_{2}{ }^{\Gamma}$-module which is not a derivation. Define $\mathrm{d}$ : $\mathrm{M} \rightarrow \mathrm{M}$ such that $\mathrm{d}\left(\left(\mathrm{m}_{1}, \mathrm{~m}_{2}\right)\right)=\left(0, \tau\left(\mathrm{m}_{2}\right)\right)$ and $\mathrm{g}: \mathrm{M} \rightarrow \mathrm{M}$ such that $\mathrm{g}\left(\left(\mathrm{m}_{1}, \mathrm{~m}_{2}\right)\right)=\left(\delta\left(\mathrm{m}_{1}\right)\right.$, 0 ), $\mathrm{m}_{1} \in \mathrm{M}_{1}, \mathrm{~m}_{2} \in \mathrm{M}_{2}$. Then it is clear that $\mathrm{d}$ is a semi-derivation of $\mathrm{M}$ (with associated map g) which is not a derivation.

\section{Semi Derivations of Prime $\Gamma$-rings}

We obtain our results.

\section{Lemma 3.1}

Let $\mathrm{M}$ be a prime $\Gamma$-ring satisfying the assumption $(*)$ and let $\mathrm{m} \in \mathrm{M}$. If

$\left[[\mathrm{m}, \mathrm{x}]_{\alpha}, \mathrm{x}\right]_{\alpha}=0$ for all $\mathrm{x} \in \mathrm{M}, \alpha \in \Gamma$, then $\mathrm{x} \in \mathrm{C}(\mathrm{M})$. 


\section{Proof}

A linearization of $\left[[\mathrm{m}, \mathrm{x}]_{\alpha}, \mathrm{x}\right]_{\alpha}=0$ for all $\mathrm{x} \in \mathrm{M}, \alpha \in \Gamma$, gives

$\left[[\mathrm{m}, \mathrm{x}]_{\alpha}, \mathrm{y}\right]_{\alpha}+\left[[\mathrm{m}, \mathrm{y}]_{\alpha}, \mathrm{x}\right]_{\alpha}=0$ for all $\mathrm{x}, \mathrm{y} \in \mathrm{M}, \alpha \in \Gamma$.

Replacing y by $\mathrm{y} \beta \mathrm{x}$ in (1) and using $\left[[\mathrm{m}, \mathrm{x}]_{\alpha}, \mathrm{x}\right]_{\alpha}=0$ for all $\mathrm{x} \in \mathrm{M}, \alpha \in \Gamma$, we obtain

$0=\left[[\mathrm{m}, \mathrm{x}]_{\alpha}, \mathrm{y} \beta \mathrm{x}\right]_{\alpha}+\left[[\mathrm{m}, \mathrm{y} \beta \mathrm{x}]_{\alpha}, \mathrm{x}\right]_{\alpha}=\left[[\mathrm{m}, \mathrm{x}]_{\alpha}, \mathrm{y}\right]_{\alpha} \beta \mathrm{x}+\left[[\mathrm{m}, \mathrm{y}]_{\alpha} \beta \mathrm{x}+\mathrm{y} \beta[\mathrm{m}, \mathrm{x}]_{\alpha}\right.$

$=\left[[\mathrm{m}, \mathrm{x}]_{\alpha}, \mathrm{y}\right]_{\alpha} \beta \mathrm{x}+[[\mathrm{m}, \mathrm{y}] \alpha, \mathrm{x}]_{\alpha} \beta \mathrm{x}+[\mathrm{y}, \mathrm{x}]_{\alpha} \beta[\mathrm{m}, \mathrm{x}]_{\alpha}$, for all $\mathrm{x} \in \mathrm{M}, \alpha \in \Gamma$,

Applying (1), we then get $[y, x]_{\alpha} \beta[\mathrm{m}, \mathrm{x}]_{\alpha}=0$, for all $\mathrm{x} \in \mathrm{M}, \alpha \in \Gamma$. Taking $\mathrm{y} \beta \mathrm{z}$ for $\mathrm{y}$ in this relation and using $[y \beta z, x]_{\alpha}=[y, x]_{\alpha} \beta z+y \beta[z, x]_{\alpha}$, we see that

$[y, x]_{\alpha} \beta z \beta[m, x]_{\alpha}=0$, for all $x, y, z \in M, \alpha \in \Gamma$. In particular, $[m, x]_{\alpha} \beta z \beta[m, x]_{\alpha}=0$, for all $\mathrm{x} \in \mathrm{M}, \alpha \in \Gamma$. Since $\mathrm{M}$ is prime, $[\mathrm{m}, \mathrm{x}]_{\alpha}=0$. This implies $\mathrm{x} \in \mathrm{C}(\mathrm{M})$.

\section{Theorem 3.2}

Let $\mathrm{M}$ be a non-commutative 2-torsion free prime $\Gamma$-ring satisfying the condition $\left({ }^{*}\right)$ and $\mathrm{d}$ is a semi-derivation of $\mathrm{M}$ with $\mathrm{g}: \mathrm{M} \rightarrow \mathrm{M}$ is an onto endomorphism. If the mapping $\mathrm{x}$ $\rightarrow[\mathrm{a} \beta \mathrm{d}(\mathrm{x}), \mathrm{x}]_{\alpha}$ for all $\alpha, \beta \in \Gamma$, is commuting on $\mathrm{M}$, then $\mathrm{a}=0$ or $\mathrm{d}=0$.

\section{Proof}

Firstly, we assume that $a$ be a nonzero element of M. Then we know that the mapping $\mathrm{x}$ $\rightarrow[\mathrm{a} \beta \mathrm{d}(\mathrm{x}), \mathrm{x}]_{\alpha}$ is commuting on $\mathrm{M}$. Thus we have $\left[[\mathrm{a} \beta \mathrm{d}(\mathrm{x}), \mathrm{x}]_{\alpha}, \mathrm{x}\right]_{\alpha}=0$. By lemma 3.1, we have

$$
[\mathrm{a} \beta \mathrm{d}(\mathrm{x}), \mathrm{x}]_{\alpha}=0 \text {, for all } \mathrm{x} \in \mathrm{M}, \alpha, \beta \in \Gamma \text {. }
$$

By linearizing (2), we have

$$
[a \beta d(x), y]_{\alpha}+[a \beta d(y), x]_{\alpha}=0 \text {, for all } x, y \in M, \alpha, \beta \in \Gamma \text {. }
$$

From this relation it follows that

$\mathrm{a} \beta[\mathrm{d}(\mathrm{x}), \mathrm{y}]_{\alpha}+[\mathrm{a}, \mathrm{y}]_{\alpha} \beta d(\mathrm{x})+\mathrm{a} \beta[\mathrm{d}(\mathrm{y}), \mathrm{x}]_{\alpha}+[\mathrm{a}, \mathrm{x}]_{\alpha} \beta d(\mathrm{y})=0$, for all $\mathrm{x}, \mathrm{y} \in \mathrm{M}, \alpha, \beta \in \Gamma$.

Replacing y by $y \delta x$ in (3) and using (2), we get

$[a \beta d(x), y \delta x]_{\alpha}+[a \beta d(y \delta x), x]_{\alpha}=0$, for all $x, y \in M, \alpha, \beta \in \Gamma$.

We get

$$
\begin{aligned}
& \mathrm{y} \delta {[\mathrm{a} \beta \mathrm{d}(\mathrm{x}), \mathrm{x}]_{\alpha}+[\mathrm{a} \beta \mathrm{d}(\mathrm{x}), \mathrm{y}]_{\alpha} \delta \mathrm{x}+[\mathrm{a} \beta(\mathrm{d}(\mathrm{y}) \delta \mathrm{x}+\mathrm{g}(\mathrm{y}) \delta \mathrm{d}(\mathrm{x})), \mathrm{x}]_{\alpha} } \\
&= {[\mathrm{a} \beta \mathrm{d}(\mathrm{x}), \mathrm{y}]_{\alpha} \delta \mathrm{x}+[\mathrm{a} \beta \mathrm{d}(\mathrm{y}) \delta \mathrm{x}, \mathrm{x}]_{\alpha}+[\mathrm{a} \beta \mathrm{g}(\mathrm{y}) \delta \mathrm{d}(\mathrm{x}), \mathrm{x}]_{\alpha} } \\
&= \mathrm{a} \beta[\mathrm{d}(\mathrm{x}), \mathrm{y}]_{\alpha} \delta \mathrm{x}+[\mathrm{a}, \mathrm{y}]_{\alpha} \beta \mathrm{d}(\mathrm{x}) \delta \mathrm{x}+\mathrm{a} \beta \mathrm{d}(\mathrm{y}) \delta[\mathrm{x}, \mathrm{x}]_{\alpha}+[\mathrm{a} \beta \mathrm{d}(\mathrm{y}), \mathrm{x}]_{\alpha} \delta \mathrm{x}+ \\
& \mathrm{a} \beta \mathrm{g}(\mathrm{y}) \delta[\mathrm{d}(\mathrm{x}), \mathrm{x}]_{\alpha}+[\mathrm{a} \beta \mathrm{g}(\mathrm{y}), \mathrm{x}]_{\alpha} \delta \mathrm{d}(\mathrm{x}) \\
&= \mathrm{a} \beta[\mathrm{d}(\mathrm{x}), \mathrm{y}]_{\alpha} \delta \mathrm{x}+[\mathrm{a}, \mathrm{y}]_{\alpha} \beta \mathrm{d}(\mathrm{x}) \delta \mathrm{x}+\mathrm{a} \beta[\mathrm{d}(\mathrm{y}), \mathrm{x}]_{\alpha} \delta \mathrm{x}+[\mathrm{a}, \mathrm{x}]_{\alpha} \beta \mathrm{d}(\mathrm{y}) \delta \mathrm{x}+\mathrm{a} \beta \mathrm{g}(\mathrm{y}) \delta[\mathrm{d}(\mathrm{x}), \\
&\mathrm{x}]_{\alpha}+\mathrm{a} \beta[\mathrm{g}(\mathrm{y}), \mathrm{x}]_{\alpha} \delta \mathrm{d}(\mathrm{x})+[\mathrm{a}, \mathrm{x}]_{\alpha} \beta \mathrm{g}(\mathrm{y}) \delta \mathrm{d}(\mathrm{x})=0 \text { for all } \mathrm{x}, \mathrm{y} \in M, \alpha, \beta \in \Gamma .
\end{aligned}
$$


Right multiplication of (3) by $\delta$ gives

$a \beta[d(x), y]_{\alpha} \delta x+[a, y]_{\alpha} \beta d(x) \delta x+a \beta[d(y), x]_{\alpha} \delta x+[a, x]_{\alpha} \beta d(y) \delta x=0$, for all $x, y \in M$, $\alpha, \beta \in \Gamma$.

Subtracting (6) from (5), we obtain

$\mathrm{a} \beta \mathrm{g}(\mathrm{y}) \delta[\mathrm{d}(\mathrm{x}), \mathrm{x}]_{\alpha}+\mathrm{a} \beta[\mathrm{g}(\mathrm{y}), \mathrm{x}]_{\alpha} \delta \mathrm{d}(\mathrm{x})+[\mathrm{a}, \mathrm{x}]_{\alpha} \beta \mathrm{g}(\mathrm{y}) \delta \mathrm{d}(\mathrm{x})=0$ for all $\mathrm{x}, \mathrm{y} \in \mathrm{M}, \alpha, \beta, \delta \in \Gamma$.

Taking a $\lambda \mathrm{g}(\mathrm{y})$ instead of $\mathrm{g}(\mathrm{y})$ in (7), we have

$$
\begin{aligned}
& \mathrm{a} \beta \mathrm{a} \lambda \mathrm{g}(\mathrm{y}) \delta[\mathrm{d}(\mathrm{x}), \mathrm{x}]_{\alpha}+\mathrm{a} \beta[\mathrm{a} \lambda \mathrm{g}(\mathrm{y}), \mathrm{x}]_{\alpha} \delta \mathrm{d}(\mathrm{x})+[\mathrm{a}, \mathrm{x}]_{\alpha} \beta \mathrm{a} \lambda \mathrm{g}(\mathrm{y}) \delta \mathrm{d}(\mathrm{x}) \\
& =\mathrm{a} \beta \mathrm{a} \lambda \mathrm{g}(\mathrm{y}) \delta[\mathrm{d}(\mathrm{x}), \mathrm{x}]_{\alpha}+\mathrm{a} \beta \mathrm{a} \lambda[\mathrm{g}(\mathrm{y}), \mathrm{x}]_{\alpha} \delta \mathrm{d}(\mathrm{x})+\mathrm{a} \beta[\mathrm{a}, \mathrm{x}]_{\alpha} \lambda \mathrm{g}(\mathrm{y}) \delta \mathrm{d}(\mathrm{x}) \\
& +[\mathrm{a}, \mathrm{x}]_{\alpha} \beta \mathrm{a} \lambda \mathrm{g}(\mathrm{y}) \delta \mathrm{d}(\mathrm{x}) \\
& =\mathrm{a} \beta \mathrm{a} \lambda \mathrm{g}(\mathrm{y}) \delta[\mathrm{d}(\mathrm{x}), \mathrm{x}]_{\alpha}+\mathrm{a} \beta \mathrm{a} \lambda[\mathrm{g}(\mathrm{y}), \mathrm{x}]_{\alpha} \delta \mathrm{d}(\mathrm{x})+\mathrm{a} \beta[\mathrm{a}, \mathrm{x}]_{\alpha} \lambda \mathrm{g}(\mathrm{y}) \delta \mathrm{d}(\mathrm{x}) \\
& +[\mathrm{a}, \mathrm{x}]_{\alpha} \beta \mathrm{a} \lambda \mathrm{g}(\mathrm{y}) \delta \mathrm{d}(\mathrm{x}) \\
& =0 \text { for all } \mathrm{x}, \mathrm{y} \in \mathrm{M}, \alpha, \beta, \lambda, \delta \in \Gamma .
\end{aligned}
$$

Left multiplication of (6) by a $\lambda$ leads to

$$
\begin{aligned}
& \mathrm{a} \lambda \mathrm{a} \beta \mathrm{g}(\mathrm{y}) \delta[\mathrm{d}(\mathrm{x}), \mathrm{x}]_{\alpha}+\mathrm{a} \lambda \mathrm{a} \beta[\mathrm{g}(\mathrm{y}), \mathrm{x}]_{\alpha} \delta \mathrm{d}(\mathrm{x})+\mathrm{a} \lambda[\mathrm{a}, \mathrm{x}]_{\alpha} \beta \mathrm{g}(\mathrm{y}) \delta \mathrm{d}(\mathrm{x}) \\
& =\mathrm{a} \beta \mathrm{a} \lambda \mathrm{g}(\mathrm{y}) \delta[\mathrm{d}(\mathrm{x}), \mathrm{x}]_{\alpha}+\mathrm{a} \beta \mathrm{a} \lambda[\mathrm{g}(\mathrm{y}), \mathrm{x}]_{\alpha} \delta \mathrm{d}(\mathrm{x})+\mathrm{a} \beta[\mathrm{a}, \mathrm{x}]_{\alpha} \lambda \mathrm{g}(\mathrm{y}) \delta \mathrm{d}(\mathrm{x})=0 \text { for all } \mathrm{x}, \mathrm{y} \in \mathrm{M}, \\
& \alpha, \beta, \delta, \lambda \in \Gamma .
\end{aligned}
$$

Subtracting (9) from (8), we get $[\mathrm{a}, \mathrm{x}]_{\alpha} \beta \mathrm{a} \lambda \mathrm{g}(\mathrm{y}) \delta \mathrm{d}(\mathrm{x})=0$ for all $\mathrm{x}, \mathrm{y} \in \mathrm{M}, \alpha, \beta, \lambda, \delta \in \Gamma$.

Since $\mathrm{M}$ is prime, we obtain that for any $\mathrm{x} \in \mathrm{M}$ either $\mathrm{d}(\mathrm{x})=0$ or $[\mathrm{a}, \mathrm{x}]_{\alpha}=0$.

It means that $\mathrm{M}$ is the union of its additive subgroups $\mathrm{P}=\{\mathrm{x} \in \mathrm{M}: \mathrm{d}(\mathrm{x})=0\}$

and $\mathrm{Q}=\left\{\mathrm{x} \in \mathrm{M}:[\mathrm{a}, \mathrm{x}]_{\alpha} \beta \mathrm{a}=0\right\}$. Since a group cannot be the union of two proper subgroups, we find that either $\mathrm{P}=\mathrm{M}$ or $\mathrm{Q}=\mathrm{M}$.

If $\mathrm{P}=\mathrm{M}$, then $\mathrm{d}=0$. If $\mathrm{Q}=\mathrm{M}$, then this implies that $[\mathrm{a}, \mathrm{x}]_{\alpha} \beta \mathrm{a}=0$, for all $\mathrm{x} \in \mathrm{M}, \alpha, \beta \in \Gamma$.

Let us take $x \delta y$ instead of $x$ in this relation. Then we get $[a, x \delta y]_{\alpha} \beta a=0$, for all $x \in M$, $\alpha, \beta \in \Gamma$.

We get $[a, x \delta y]_{\alpha} \beta a=x \delta[a, y]_{\alpha} \beta a+[a, x]_{\alpha} \delta y \beta a=[a, x]_{\alpha} \delta y \beta a=0$, for all $x, y \in M$, $\alpha, \beta, \delta \in \Gamma$.

Since $\mathrm{a} \in \mathrm{M}$ is nonzero and $\mathrm{M}$ is prime, we obtain $\mathrm{a} \in \mathrm{C}(\mathrm{M})$. Thus by this and (2), the relation (7) reduces to $\mathrm{a} \beta[\mathrm{g}(\mathrm{y}), \mathrm{x}]_{\alpha} \delta \mathrm{d}(\mathrm{x})=0$, for all $\mathrm{x}, \mathrm{y} \in \mathrm{M}, \alpha, \beta, \delta \in \Gamma$.

Since $g$ is onto, we see that $a \beta z \gamma[u, x]_{\alpha} \delta d(x)=z \beta a \gamma[u, x]_{\alpha} \delta d(x)=0$, for all $x, u, z \in M$, $\alpha, \beta, \delta, \gamma \in \Gamma$. Now by primeness of $\mathrm{M}$, we obtain that $[\mathrm{u}, \mathrm{x}]_{\alpha} \delta \mathrm{d}(\mathrm{x})=0$, for all $\mathrm{x}, \mathrm{u} \in \mathrm{M}$, $\alpha, \beta, \delta \in \Gamma$. 
Replacing $\mathrm{u}$ by $\mathrm{u} \lambda \mathrm{w}$, we get $[\mathrm{u}, \mathrm{x}]_{\alpha} \lambda \mathrm{w} \delta \mathrm{d}(\mathrm{x})=0$, for all $\mathrm{x}, \mathrm{u}, \mathrm{w} \in \mathrm{M}, \alpha, \beta, \delta, \lambda \in \Gamma$. By the primeness of $\mathrm{M},[\mathrm{u}, \mathrm{x}]_{\alpha}=0$ or $\mathrm{d}(\mathrm{x})=0$. Again using the fact that a group cannot be the union of two proper subgroups, it follows that $\mathrm{d}=0$, since $\mathrm{M}$ is non-commutative, i.e., [u, $\mathrm{x}]_{\alpha}$. Hence we see that, in any case, $\mathrm{d}=0$. This completes the proof.

\section{Theorem 3.3}

Let $\mathrm{M}$ be a prime 2-torsion free $\Gamma$-ring satisfying the condition $(*), \mathrm{d}$ is a nonzero semiderivation of $M$, with associated endomorphism $g$ and $a \in M$. If $g \neq \pm I$ ( $I$ is an identity map of $M)$, then $(d(M), a)_{\alpha}=0$ if and only if $d\left((M, a)_{\alpha}\right)=0$.

\section{Proof}

Suppose $(d(M), a)_{\alpha}=0$. Firstly, we will prove that $d(a)=0$. If $a=0$ then $d(a)=0$. So we assume that $\mathrm{a} \neq 0$. By our hypothesis, we have $(\mathrm{d}(\mathrm{x}), \mathrm{a})_{\alpha}=0$, for all $\mathrm{x} \in \mathrm{M}, \alpha \in \Gamma$.

From this relation, we get

$$
\begin{aligned}
0 & =(d(x \beta a), a)_{\alpha}=(d(x) \beta g(a)+x \beta d(a), a)_{\alpha} \\
& =d(x) \beta[g(a), a]_{\alpha}+(d(x), a)_{\alpha} \beta a+x \beta(d(a), a)_{\alpha}+[x, a]_{\alpha} \beta d(a),
\end{aligned}
$$

and so, $[\mathrm{x}, \mathrm{a}]_{\alpha} \beta \mathrm{d}(\mathrm{a})=0$, for all $\mathrm{x} \in \mathrm{M}, \alpha, \beta \in \Gamma$.

Now, replacing $\mathrm{x}$ by $\mathrm{x} \delta \mathrm{y}$ in (10), we get

$[\mathrm{x} \delta \mathrm{y}, \mathrm{a}]_{\alpha} \beta \mathrm{d}(\mathrm{a})=0$, for all $\mathrm{x} \in \mathrm{M}, \alpha, \beta \in \Gamma$. By calculation we get,

$$
\mathrm{x} \delta[\mathrm{y}, \mathrm{a}]_{\alpha} \beta \mathrm{d}(\mathrm{a})+[\mathrm{x}, \mathrm{a}]_{\alpha} \delta \mathrm{y} \beta \mathrm{d}(\mathrm{a})=[\mathrm{x}, \mathrm{a}]_{\alpha} \delta \mathrm{y} \beta \mathrm{d}(\mathrm{a})=0 \text {, for all } \mathrm{x} \in \mathrm{M}, \alpha, \beta, \delta \in \Gamma
$$

The primeness of $M$ implies that $[x, a]_{\alpha}=0$ or $d(a)=0$ that is, $a \in C(M)$ or $d(a)=0$.

Now suppose that $\mathrm{a} \in \mathrm{C}(\mathrm{M})$. Since $(\mathrm{d}(\mathrm{a}), \mathrm{a})_{\alpha}=0$, we have $\mathrm{d}(\mathrm{a}) \alpha \mathrm{a}+\mathrm{a} \alpha \mathrm{d}(\mathrm{a})$

$=2 \operatorname{a\alpha d}(a)=0$. Since $M$ is 2-torsion free, $\operatorname{a\alpha d}(a)=0$. Since we assumed that $0 \neq a$ and $M$ is a prime $\Gamma$-ring, we get $\mathrm{d}(\mathrm{a})=0$. Hence we have $\mathrm{d}\left((\mathrm{x}, \mathrm{a})_{\alpha}\right)$

$$
\begin{aligned}
& =\mathrm{d}(\mathrm{x} \alpha \mathrm{a}+\mathrm{a} \alpha \mathrm{x})=\mathrm{d}(\mathrm{x} \alpha \mathrm{a})+\mathrm{d}(\mathrm{a} \alpha \mathrm{x})=\mathrm{d}(\mathrm{x}) \alpha \mathrm{a}+\mathrm{g}(\mathrm{x}) \alpha \mathrm{d}(\mathrm{a})+\mathrm{d}(\mathrm{a}) \alpha \mathrm{g}(\mathrm{x})+\mathrm{a} \alpha \mathrm{d}(\mathrm{x}) \\
& \left.=(\mathrm{g}(\mathrm{x}), \mathrm{d}(\mathrm{a}))_{\alpha}+(\mathrm{d}(\mathrm{x}), \mathrm{a})_{\alpha}=(\mathrm{d}(\mathrm{x}), a)_{\alpha}\right)=0, \text { for all } \mathrm{x} \in \mathrm{M}, \alpha \in \Gamma . \text { Hence }(\mathrm{d}(\mathrm{x}), a)_{\alpha} \\
& =0 .
\end{aligned}
$$

Conversely, for all $\mathrm{x} \in \mathrm{M}$,

$0=d\left((a \beta x, a)_{\alpha}\right)=d\left(a \beta(x, a)_{\alpha}+[a, a]_{\alpha} \beta x\right)=d\left(a \beta(x, a)_{\alpha}\right)=d(a) \beta(x, a)_{\alpha}+g(a) \beta d((x), a)_{\alpha}$.

We have

$$
\mathrm{d}(\mathrm{a}) \beta(\mathrm{x}, \mathrm{a})_{\alpha}=0 \text {, for all } \mathrm{x} \in \mathrm{M}, \alpha, \beta \in \Gamma \text {. }
$$

Replacing $\mathrm{x}$ by $\mathrm{x} \delta \mathrm{y}$ in (12), we get

$$
0=d(a) \beta(x \delta y, a)_{\alpha}=d(a) \beta x \delta[y, a]_{\alpha}+d(a) \beta(x, a)_{\alpha} \delta y=d(a) \beta x \delta[y, a]_{\alpha} .
$$

This implies that $\mathrm{d}(\mathrm{a}) \beta \mathrm{x} \delta[\mathrm{x}, \mathrm{a}]_{\alpha}=0$, for all $\mathrm{x} \in \mathrm{M}, \alpha, \beta, \delta \in \Gamma$. 
For the primeness of $M$, we have either $d(a)=0$ or $a \in C(M)$. If $d(a)=0$, then we have $0=d((x), a)_{\alpha}=(d(x), a)_{\alpha}+(d(a), g(x))_{\alpha}=(d(x), a)_{\alpha}$, for all $\mathrm{x} \in M, \alpha \in \Gamma$. This yields that $(d(x), a)_{\alpha}=0$. If $a \in C(M)$, then we have $0=d\left((a, a)_{\alpha}\right)$

$=2 d(a) \alpha(a+g(a))$. Since $M$ is 2-torsion free, we obtain $d(a) \alpha(a+g(a))=0$. Since $M$ is prime we have $d(a)=0$ or $a+g(a)=0$. But since $g$ is different from $\neq \pm I$, we find that $d(a)=0$. Finally, $(d(x), a)_{\alpha}=0$ implies the required result.

\section{REFERENCES}

1. Bell, H. E. and Martindale, W. S. III, Semiderivations and commutativity in prime rings, Canad. Math. Bull. , 31(4), (1988), 500-508.

2. Bergen, J., Derivations in prime rings, Canad. Math. Bull., 26 (1983), 267-270.

3. Bergen, J. and Grzesczuk, P., Skew derivations with central invariants, J. London Math. Soc., 59(2), (1999), 87-99.

4. M. Bresar, On a generalization of the notation of centralizing mappings, Proc. Amer. Math. Soc., 114 (1992), 641-649.

5. Bresar, M., Semiderivations of prime rings, Proc. Amer. Math. Soc., 108 (4) (1990), 859-860.

6. Chang, J.-C., On semi-derivations on prime rings, Chinese J. Math., 12 (1984), 255-262.

7. Chuang, Chen-Lian, on the structure of semiderivations in prime rings, Proc. Amer. Math. Soc., 108 (4) (1990), 867-869.

8. Firat, A., Some results for semi derivations of prime rings, International J. of Pure and Applied Mathematics, 28(3), (2006), 363-368. 